\title{
Accelerometer Implementation as Feedback on 5 Degree of Freedom Arm Robot
}

\author{
Kunal Kunal ${ }^{1}$, Afif Zuhri Arfianto ${ }^{2}$, Joessianto Eko Poetro ${ }^{3}$, Farhad Waseel ${ }^{4}$, Rachmad Andri Atmoko ${ }^{5}$ \\ ${ }^{1}$ School of Information, Communication \& Technology, Indraprastha University, Delhi, India \\ ${ }^{2}$ Politeknik Perkapalan Negeri Surabaya, Surabaya, Indonesia \\ ${ }^{3}$ Program Studi Teknik Kelistrikan Kapal, Jurusan Kelistrikan Kapal, Politeknik Perkapalan Negeri Surabaya \\ ${ }^{4}$ Department of mathematics, Kabul University, Kabul, Afghanistan \\ ${ }^{5}$ School of Mechanical and Electrical Engineering, Guilin University of Electronic Technology, Guilin, China \\ Email: Kunal.karn007@gmail.com, afifzuhri@ieee.org, joessianto@ppns.ac.id, farhadwaseel@gmail.com, \\ mokoraden@hotmail.com
}

\begin{abstract}
The research investigated the automatic control system implemented with the 5 DOF (Degree of Freedom) arm robot control system using the closed-loop control method with the MPU 6050 sensor, which integrated the rotation of the MG995 motor servo as a feedback function. The control of this robot used android-based application, in which the app sends data of the rotate angle for each servo motor rotated to a certain angle. The $\mathrm{HC}-05$ Bluetooth received the data and the Arduino UNO R3 microcontroller processed them. The microcontroller managed every rotation of each servo motor that integrated with an MPU6050 sensor with serial monitor communication to display the rotation of each servo motor. The test results obtained by the standard deviation value showed how large the sample diversity was. The result of this study showed a standard deviation correlation with the number of sample diversity. The higher the standard deviation value, the more sample data spread (data diverse or varies). Otherwise, the smaller the standard deviation value, the more homogenous the sample data. If the standard deviation equals zero, it indicates that the sample has identical data. The highest standard deviation value from servo motor 1 is 5.20, servo motor 2 and 3 are 1.00, servo motor 4 is 2.89 , and servo motor 5 is 2.9 .
\end{abstract}

Keywords-Close Loop, MPU 6050 Sensor, Servo motor, Arduino

\section{INTRODUCTION}

The use of technology in the digital era is based on computerization in both research and industry. The basic use of technology is that it must increase the productivity of human resources and the efficiency of products. The standardization of high-quality products in large quantities requires robotic technology to anticipate human error during the manufacturing process and logging.

Some researchers have conducted research using robotic arms. Kumar studied Object-Based computer vision grasping a $6 \mathrm{DoF}$ robot arm using camera [1]. The robot system was controlled with Arduino and Raspberry. the phase-wise development of remote-controlled robot arm was investigated by Sharma [2]. The robot system was controlled by using Arduino ATMEGA2560. The development of a robot arm for color-based goods sorter in the factory using tcs3200 sensor with web-based monitoring system was investigated by Panie and Mutiara [3]. The robot system used a color sensor and a Nodemcu microcontroller.
Tomaszuk investigated the combined drive system of robotic arms used in mobile robots [4]. The robot system was driven by using the STM32 microcontroller. Ababneh examined the gesture-controlled mobile robotic arm to help elderly and wheelchairs using Kinect sensors [5]. The robot system used a Kinect sensor and a microcontroller control. Chua studied the development of microcontroller-based wireless robot arm writing controlled by framework tracking [6]. The robot system used a Kinect sensor and was controlled by a microcontroller connected to the computer.

Kandalaft designed robot arms using sound and gesture recognition [7]. The robotic system used sound sensors and gestures. The robot was controlled using a microcontroller. Artal-Sevil designed a low-cost robot arm controlled by Surface EMG sensor [8]. The robot system consisted of an EMG sensor. The robot was controlled using Arduino UNO. Szczesny and Recko investigated control of robot arms for Mars rover analog [9]. The robot system was designed using 6 DoF and was controlled by an STM32F7 microcontroller.

The purpose of this control system is to create a closedloop control system (Closed Loop) for the operation of the Arm Robot 5 DOF (Degree of Freedom) which is controlled by an Android smartphone using Bluetooth connection. The use of the Arduino UNO Microcontroller is the main controller for running the logic program that has been made. The MPU6050 is as feedback to the servo motor angle motion. In the operation, the Robot Arm enters the angle value of each input of each servo against the output angle, based on the MPU6050 sensor integrated with the Servo motor.

The purpose of this research is to control the Robot Arm with an android smartphone, obtain the angle value on each servo motor when the Robot Arm System is moved according to the specified angle, and obtain a closed-loop control system on the servo motor movement accurately.

\section{METHOD}

The research methodology of the Arm 5 DoF (Degree of Freedom) [10], [11] Control System with Android Smartphone [2], [7], [12]-[15] was carried out by designing a motion system based on a closed-loop method. 


\section{A. Movement system design}

Robot Arm 5 DoF (Degree of Freedom) with Android smartphones required several devices used to run the motion system as illustrated in Figure 1.

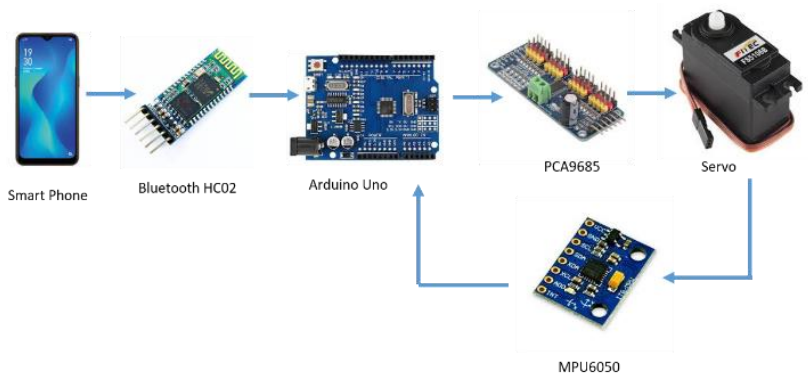

Fig. 1. System block diagram

The system block diagram shows the processing tools and materials from the initial to the final process. The Bluetooth is connected from the mobile phone to the $\mathrm{HC} 05$ Bluetooth module [2], [16]-[21] as a receiver from the Arduino application. The PCA9685 module is [22] used to control a servo motor with six servo motors.

\section{B. System Schematic Design}

The schematic design of electrical circuits functions to translate the design concepts of tools and materials into electrical circuits is shown in Figure 3. It consists of several components that make up the system namely input devices, control devices, and output components.

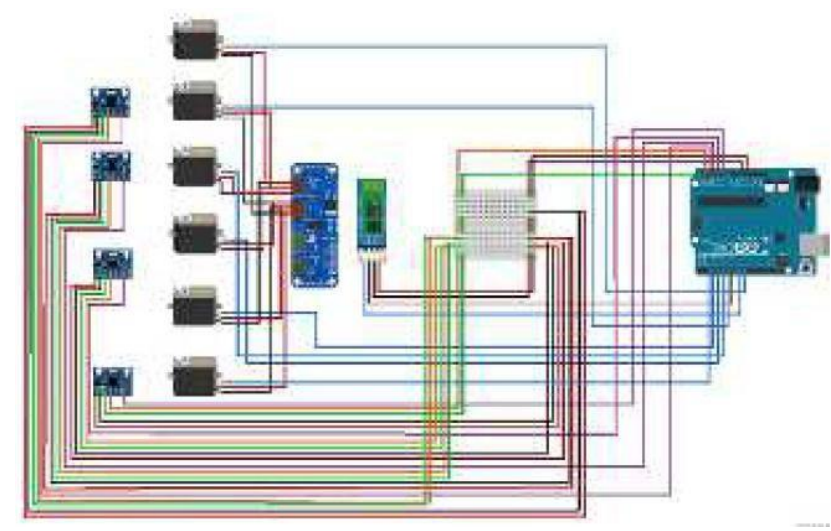

Fig. 2. System electrical schematic

In the system electrical schematic shown in Figure 2, the input is 5 Volt adapters for PCA9685 modules. The input device is from the angle value enters in each servo motor. The output components are six MG995 servo motors [23]-[27] and five MPU 6050 [28]-[31].

\section{Firmware Design}

There are several explanations on how the motion system works based on their respective functions on each device and material that has been run. The system workflow is shown in Figure 3.

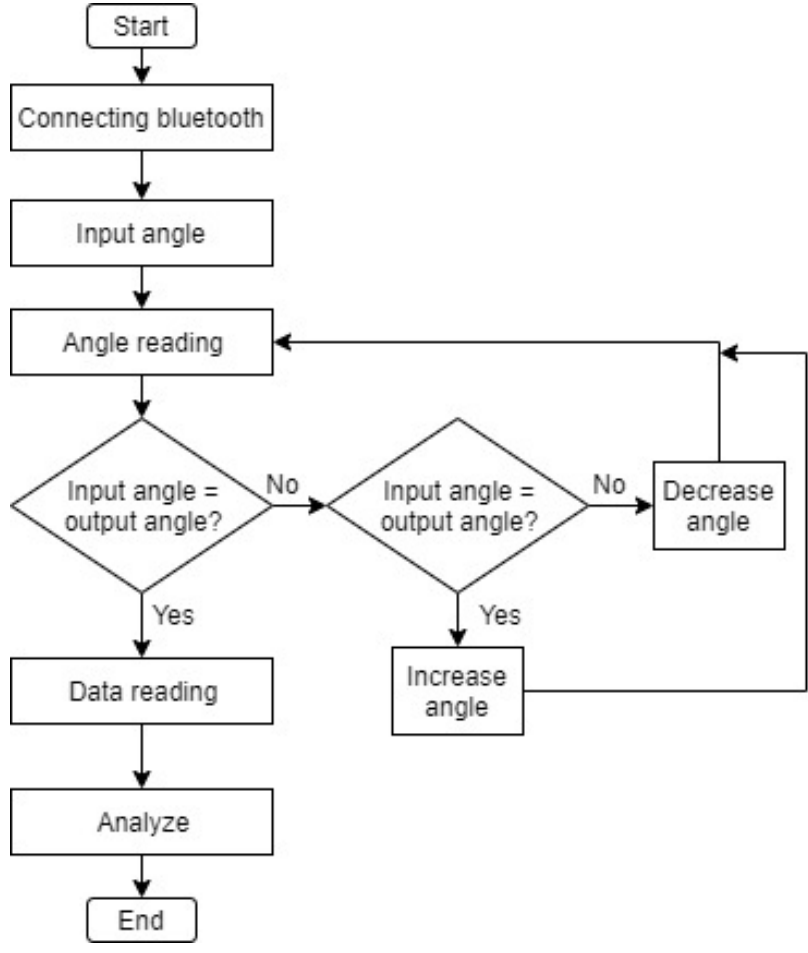

Fig. 3. System workflow

\section{IMPLEMENTATION}

The overall design and testing results of the servo motor movement were integrated with the MPU6050 sensor and time calculation.

\section{A. Servo 1 Test}

The data collection was carried out by giving a predetermined input angle value at three times experiments at each corner. The amount of time was recorded from the initial to the final angle. Figure 4 shows the results of data retrieval performed on servo motor 1 for 3 times with a predetermined angle of $0^{\circ}$ and $135^{\circ}$.

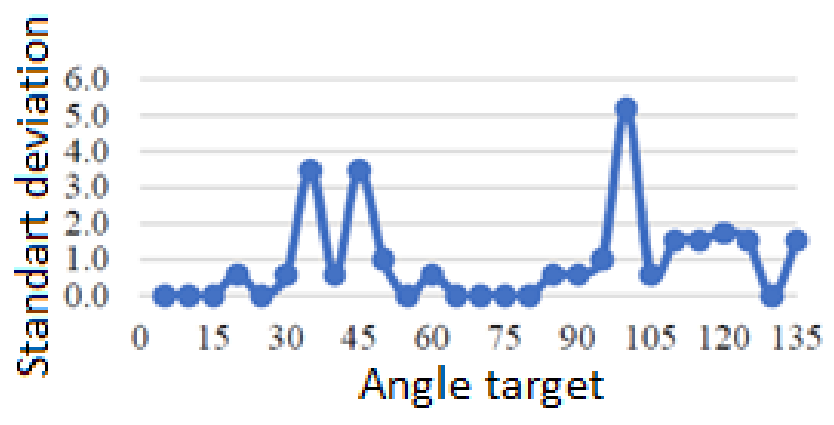

Fig. 4. Standard deviation against servo 1 angle target

Figure 4 shows that the standard deviation values at the targeted angles 5, 10, 15, 25, 55, 55, and 80 and the target angle of 130 has a standard deviation of 0.0 meaning that the values of all samples are the same (absolutely the same or identical). The samples which have a standard deviation value of 0.58 to 1.0 are more homogeneous or (almost the same), while the data of a standard deviation of 3.46 to 5.20 means that the sample data used is increasingly spread (varied or varied data). The largest standard deviation of servo motor 1 is at an angle of 100 with a value of 5.20, which means that 
the sample data varies. The test of time shows that the data of the magnitude of the target angle with time fluctuate. The greater the angled target is determined, the longer the time is required. There is a significant decrease in the target angle of 50 with 3.59 time, and a target angle of 120 to 130 with 3.89 times.

\section{B. Servo 2 and 3 Tests}

Below are the results of the data collection which was conducted on servo motor numbers 2 and 3 for 3 times with a predetermined angle $0^{\circ}$ and $125^{\circ}$.

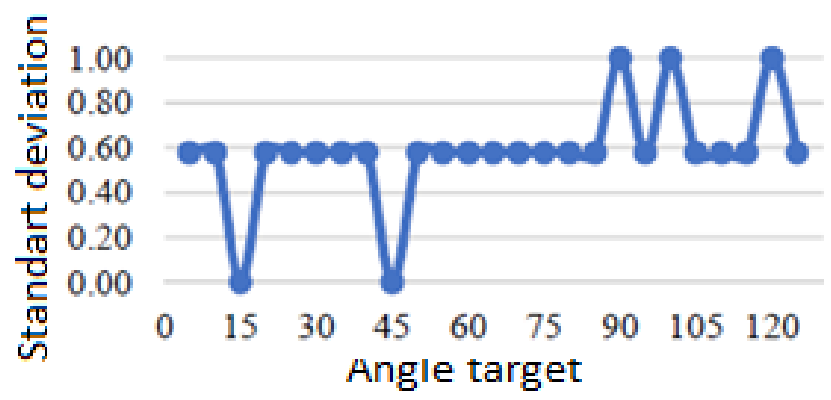

Fig. 5. Standard deviation of target servo angle 2 and 3

Figure 5 shows that the standard deviation at the 15 th angle target is 0.0 , meaning that the values of all samples are the same (absolutely the same or identical). The samples that have a standard deviation of 0.5 means that they are more homogeneous (or almost the same). Whereas the data with a standard deviation 1.0 means that the sample data used is increasingly diffused (varied). The largest standard deviation of servo motors $2 \& 3$ is at the target angle of 90,100 and 120 with a value of 1.0 meaning that the sample data varies. The angular of time has a significant increase and decrease. The most significant decrease occurs at an angle of 90 to 95 f 3.59 time.

\section{Servo 4 Test}

Below are the results of data retrieval performed on servo motor 4 for 3 times with a predetermined angle $0^{\circ}$ and 90 .

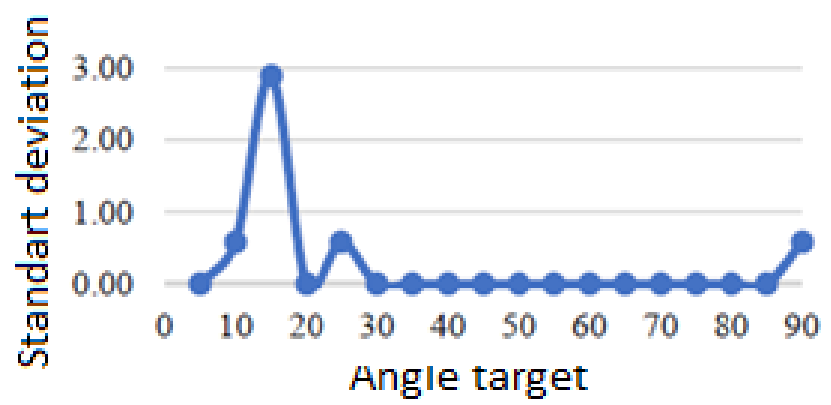

Fig. 6. Standard deviation against servo 4 angle target

Figure 6 displays that the standard deviation values of the target angle 5, 25, 30 to 85 are 0.00 meaning that the values of all samples are the same (absolutely the same or identical). The samples that have a standard deviation 0.58 means that the sample data are more homogeneous or (almost the same), while the standard deviation 2.89 means that the sample data are more diffuse (varied). The largest standard deviation on the servo motor 4 is the target angle 15 is 2.89 , which means that the sample data varies.
The data of the target angle with time fluctuate. The greater the target angle determined, the longer the time taken. There is a significant decrease in the target angle from 85 to 90 in 5.06 times.

\section{Servo 5 Test}

Below are the results of data retrieval performed on servo motor 5 for 3 times with a predetermined angle $0^{\circ}$ and $90^{\circ}$.

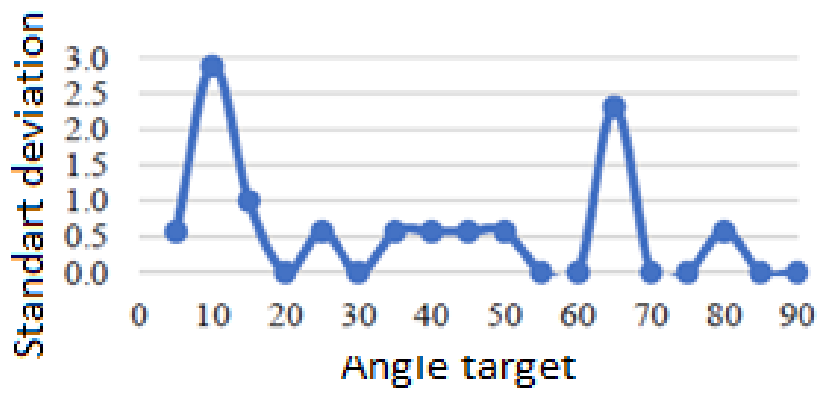

Fig. 7. Standard deviation against servo 5 angle target

Figure 7 shows that the standard deviation values at the target angle of 20,30,55,60, 70, 75, 85, and 90 are 0.00 , meaning that the values of all samples are equal (absolutely the same or identical). The samples that have a standard deviation 0.6 to 1.0 means that the sample data are more homogeneous or (almost the same). Whereas the standard deviation 2.3 to 2.9 means that the sample data used are more diffuse (varied or varied data). The largest standard deviation of servo motor 5 is at the target angle of 10 with standard deviation of 2.9, meaning that the sample data varies. The data of the angular target are fluctuating. The greater the angular target, the longer the time required.

\section{CONCLUSION}

The research has succeeded to move the $5 \mathrm{DoF}$ (Degree of Freedom) robot arm on an Android smartphone application with a Bluetooth connection. The output value on the movement of the servo motor is in accordance with the input value on the specified Android smartphone application. The test results of the research using close-loop method obtain standard deviation values indicating how large the diversity of the sample is. The greater the standard deviation, the more spread the sample data (varied), and reversely. The smaller the standard deviation, the more homogeneous the sample data (almost the same). If the standard deviation is 0 , the sample has the same data (identical). The largest standard deviation value on servo motor 1 is 5.20 , servo motor 2 and 3 is 1.00 , servo motor 4 is 2.89 and servo motor 5 is 2.9 .

\section{REFERENCES}

[1] V. Kumar, Q. Wang, W. Minghua, S. Rizwan, S. M. Shaikh, and X. Liu, "Computer vision based object grasping 6DoF robotic arm using picamera," in 2018 4th International Conference on Control, Automation and Robotics (ICCAR), 2018, pp. 111-115.

[2] S. Sharma, S. Sahai, J. Joshi, and N. Hema, "Stage-wise Development of a Remote Controlled Robotic Arm," in 2018 Fifth International Conference on Parallel, Distributed and Grid Computing (PDGC), 2018, pp. 364-367.

[3] G. I. E. Panie and A. B. Mutiara, "Development of Robotic Arm for Color Based Goods Sorter in Factory Using TCS3200 Sensor with a Web-Based Monitoring System," in 2018 Third International Conference on Informatics and Computing (ICIC), 2018, pp. 1-6. 
[4] P. Tomaszuk, A. Lukowska, M. Recko, and K. Dzicrzck, "Integrated Drive System of Robotic Arm Joint Used in a Mobile Robot," in 2018 23rd International Conference on Methods \& Models in Automation \& Robotics (MMAR), 2018, pp. 509-514.

[5] M. Ababneh, H. Shaban, D. AlShalabe, D. Khader, H. Mahameed, and M. AlQudimat, "Gesture Controlled Mobile Robotic Arm for Elderly and Wheelchair People Assistance Using Kinect Sensor," in 2018 15th International Multi-Conference on Systems, Signals \& Devices (SSD), 2018, pp. 636-641.

[6] S. H. Chua, J. S. Limqueco, E. L. Lu, S. W. Que, and D. Abuan, "Development of a Microcontroller-based Wireless Writing Robotic Arm Controlled by Skeletal Tracking," in 2018 IEEE 10th International Conference on Humanoid, Nanotechnology, Information Technology,Communication and Control, Environment and Management (HNICEM), 2018, no. 978, pp. 1-6.

[7] N. Kandalaft, P. S. Kalidindi, S. Narra, and H. N. Saha, "Robotic arm using voice and Gesture recognition," in 2018 IEEE 9th Annual Information Technology, Electronics and Mobile Communication Conference (IEMCON), 2018, pp. 1060-1064.

[8] J. S. Artal-Sevil, A. Acon, J. L. Montanes, and J. A. Dominguez, "Design of a Low-Cost Robotic Arm controlled by Surface EMG Sensors," in 2018 XIII Technologies Applied to Electronics Teaching Conference (TAEE), 2018, pp. 1-8.

[9] T. Szczesny and M. Recko, "Control of robotic arm for Mars rover analogue," in 2018 19th International Carpathian Control Conference (ICCC), 2018, pp. 259-264.

[10] D. Anggraeni, W. S. M. Sanjaya, M. Munawwaroh, M. Y. S. Nurasyidiek, and I. P. Santika, "Control of robot arm based on speech recognition using Mel-Frequency Cepstrum Coefficients (MFCC) and K-Nearest Neighbors (KNN) method," in 2017 International Conference on Advanced Mechatronics, Intelligent Manufacture, and Industrial Automation (ICAMIMIA), 2017, no. 1, pp. 217-222.

[11] K. Jahnavi and P. Sivraj, "Teaching and learning robotic arm model," in 2017 International Conference on Intelligent Computing, Instrumentation and Control Technologies (ICICICT), 2017, vol. 2018-Janua, pp. 1570-1575.

[12] K. Dhayalini and R. Mukesh, "Deterioration \&amp; nondeterioration wastes separation using pick \&amp; place robot," in 2018 2nd International Conference on Inventive Systems and Control (ICISC), 2018, no. Icisc, pp. 96-99.

[13] B. Sahan, C. Yolcu, and S. Sahin, "Hardware design of industrial tablet for fare collection based on ARM embedded system," in 2017 International Conference on Engineering and Technology (ICET), 2017, vol. 2018-Janua, pp. 1-4.

[14] A. Mandal, S. Panda, and A. Goswami, "Driving a Charged Coupled Device (CCD) by microcontroller for LIBS based application," in 2018 International Symposium on Devices, Circuits and Systems (ISDCS), 2018, no. Ccd, pp. 1-5.

[15] I. Rustam, M. T. Miskon, Z. Jusoh, W. A. K. Wan Chek, and F. D. H. Mohd Fauzi, "Embedded Cdio Approach via Mobile Educational Robot Competition," in 2018 3rd International Conference on Control, Robotics and Cybernetics (CRC), 2018, pp. 32-36.

[16] H. U. Zaman, Rafiunnisa, and A. M. Shams, "A User-Friendly LowCost Mobile App Based Home Appliance Control And Circuit Breaker," in 2018 Second International Conference on Computing Methodologies and Communication (ICCMC), 2018, no. Iccmc, pp. 203-208.

[17] M. S. Ali and M. H. Bhuyan, "Design and implementation of a lowcost automated blood flow control device through smart phone for bio-medical application," in 2017 6th International Conference on Informatics, Electronics and Vision \& 2017 7th International
Symposium in Computational Medical and Health Technology (ICIEV-ISCMHT), 2017, pp. 1-5.

[18] G. R. D. Ganesh, K. Jaidurgamohan, V. Srinu, C. R. Kancharla, and S. V. S. Suresh, "Design of a low cost smart chair for telemedicine and IoT based health monitoring: An open source technology to facilitate better healthcare," in 2016 11th International Conference on Industrial and Information Systems (ICIIS), 2016, vol. 2018Janua, pp. 89-94.

[19] N. Technologies and S. U. Munde, "Communication in Wind Turbine," pp. 97-102, 5094.

[20] C. Ganeshan and S. K. Singh, "Smart Industrial System for Monitoring, Control and Security Using Internet of Things," in 2018 2nd International Conference on Trends in Electronics and Informatics (ICOEI), 2018, no. Icoei, pp. 958-963.

[21] A. Palchaudhuri and C. . Manimegalai, "Smart Electric Motorcycle Security System Based on GSM and ZigBee Communication," in 2018 International Conference on Communication and Signal Processing (ICCSP), 2018, pp. 0204-0208.

[22] Y. Jia, G. Yang, and J. Saniie, "Real-time color-based sorting robotic arm system," in 2017 IEEE International Conference on Electro Information Technology (EIT), 2017, pp. 354-358.

[23] A. S. C. M. Som, M. Z. Rusli, A. Z. Rodzuan, N. Omar, and Y. Husaini, "Development of hand therapy device for cerebral palsy in FKE-UiTM Capstone design subject," in 2016 IEEE 8th International Conference on Engineering Education (ICEED), 2016, pp. 102-106.

[24] H. ElKheshen, I. Deni, A. Baalbaky, M. Dib, L. Hamawy, and M. A. Ali, "Semi-Automated Self-Monitore - Syringe Infusion Pump," in 2018 International Conference on Computer and Applications (ICCA), 2018, pp. 331-335.

[25] T. Debnath, S. N. Imtiaz, S. F. Nawaz, A. Al Mahmud, and M. Rahman, "A Novel Multilevel Solar Panel System: Implementation and Verification," in 2017 IEEE 44th Photovoltaic Specialist Conference (PVSC), 2017, pp. 1067-1070.

[26] T. Debnath, S. N. Imtiaz, and M. Rahman, "Implementation of an RTC based multilevel solar panel system," in 2017 IEEE Region 10 Humanitarian Technology Conference (R10-HTC), 2017, vol. 2018Janua, pp. 610-614.

[27] B.-T. Dong, C.-M. Lee, Y.-C. Chiu, and Y.-C. Huang, "An intelligent embedded cloud monitoring system design," in 2017 International Automatic Control Conference (CACS), 2017, vol. 2017-Novem, pp. 1-4.

[28] V. A. Sharma and M. Rajesh, "Building a quadcopter: An approach for an Autonomous Quadcopter," in 2018 International Conference on Advances in Computing, Communications and Informatics (ICACCI), 2018, pp. 1252-1258.

[29] A. H. T. E. De Silva, W. H. P. Sampath, N. H. L. Sameera, Y. W. R. Amarasinghe, and A. Mitani, "Development of a novel telecare system, integrated with plantar pressure measurement system," Informatics Med. Unlocked, vol. 12, no. July, pp. 98-105, 2018.

[30] N. Z. Hamid, A. L. Asnawi, W. H. W. Morshidi, A. A. Ruslan, N. A. Jundi, and H. A. M. Ramli, "Design of a Wireless Device for Monitoring Human Critical Condition at Industrial Workplace," in 2018 7th International Conference on Computer and Communication Engineering (ICCCE), 2018, pp. 252-257.

[31] D. D. Ligutan, L. J. S. Cruz, M. C. D. P. Del Rosario, J. N. S. Kudhal, A. C. Abad, and E. P. Dadios, "Design and implementation of a fuzzy logic-based joint controller on a 6-DOF robot arm with machine vision feedback," in 2017 Computing Conference, 2017, vol. 2018-Janua, no. July, pp. 249-257. 